\title{
XXXII. Additional observations on æthogen
}

\section{W.H. Balmain Esq.}

To cite this article: W.H. Balmain Esq. (1844) XXXII. Additional observations on æthogen, Philosophical Magazine Series 3, 24:158, 191-192, DOI: 10.1080/14786444408644833

To link to this article: http://dx.doi.org/10.1080/14786444408644833

$$
\text { 册 Published online: } 30 \text { Apr } 2009 .
$$

Submit your article to this journal

LII Article views: 3

Q View related articles ¿ 
seems to take place as well in tightly corked and filled vessels as in the air. Besides, when alloxantine is oxidized, it yields, not alloxanic acid but alloxan, and there is no base present that might be supposed to give rise to the production of the acid.

It is possible that this acid may not be really alloxanic acid, although agreeing with it in its reactions. In that case it appears most probable that it may be isomeric with alloxantine, as alloxanic acid is with alloxan. At all events, it is impossible to see how the 1 eq. of hydrogen has been removed, if the acid be really the alloxanic. I am still engaged in researches on this part of the subject, the results of which I shall forward to the Society at a future period, along with those of the other investigations briefly described above. The study of the products of the decomposition of uric acid is still very far from being completed, and I hope, at no very distant period, to follow up this paper with another on the same subject.

XXXII. Additional Observations on Athogen. By W. H. Balmain, Esq. *

$\mathrm{N}$ proceeding to make some quantitative experiments on rethogen, I found, that through depending too much upon simple change of property, I had been misled upon some points ; and I take this, the earliest, opportunity of pointing out in what respects my conclusions were erroneous.

All the compounds described as æthonides are one and the same substance, a new compound of boron and nitrogen, probably formed by the decomposition of the æthonide of the metal by the nitro-muriatic acid used at the end of the process. It would appear that there are two compounds of boron and nitrogen; one, which is not altered by exposure to a white heat, is decomposed by the action of water at ordinary temperatures, and also by the action of nitric acid, and which does not phosphoresce before the blowpipe; and a second, which is not decomposed by any reagents, with the exception of water and oxygen at a high temperature, and which phosphoresces beautifully before the blowpipe. The first is formed when mellon and boracic acid are heated together and combines with the metals; the second whenever a compound of the first with a metal is decomposed by abstraction of the metal, which is effected with such difficulty, that the traces left induced me to suppose that it was an essential ele-

* Communicated by the Chemical Society; having been read November 7, 1843. The author's former paper will be found in Phil. Mag. S. 3. vol. xxii. p. 467. 


\section{$192 \mathrm{Mr}$. Drach on the Enumeration of Prime Numbers.}

ment of the compound. Whether or not these two compounds are isomeric, remains yet to be ascertained.

The simplest method of preparing the phosphorescent compound is to heat together 12 parts of cyanide of mercury, $1 \frac{1}{q}$ of boracic acid, and 1 of sulphur.

The compound of phosphorus and nitrogen (discovered by Rose) probably has similar relations, and may perhaps be studied to advantage in connexion with the above; an easy method of preparing it is to place some chloro-amidide of mercury in a flask, and add from time to time a portion of phosphorus, keeping up a gentle heat all the time, and agitating now and then; and when the phosphorus ceases to produce any decomposition, raise the temperature nearly to redness.

XXXIII. On the Empirical Law in the Enumeration of Prime Numbers. $B y$ S. M. DRACH, F.R.A.S.

TEGENDRE gives, in his Théor. des Nomb, p. 395, the 1 following approximate theorem for the number $y$ of primes in a given limit $x$ :-

This is successively reducible to

$$
y=x+\{\text { hyp. } \log \cdot x-1 \cdot 08366\} \text {. }
$$

$$
e^{\frac{x}{y}}=x+2.95548 ; \text { and } e^{\frac{1}{y}}=(.338355 x)^{\frac{1}{x}} \text {. }
$$

The former equation shows that the limit, and its ratio to the number of containing primes, are respectively the abscissa and ordinate of a logarithmic curve. According to the learned author of the article Primes, in the Pen. Cyc., anno 1841, the deduction of the constant quantity 1.08366 is as yet unknown.

As however $\pi=3 \cdot 14159$, \&c., and its powers, in conjunction with a finite and generally simple fraction, represent the sums of so many series of whole numbers, it seemed probable that the aforesaid constant was somewhat connected with it ; and in fact $\frac{5}{3} \sqrt{\pi}=2.95482$ has for its hyp. log. 1.0831904, differing little from the former. This difference is insensible for small values of $x$, only whole numbers being required, and with the increase of the value of $x$ the constant becomes a proportionally less fraction of hyp. $\log . x$.

The annexed table gives the actual number of primes, $\mathbf{P}$, from 10,000 to a million; the third column is the excess of Legendre's $y$ above $\mathbf{P}$; and the fourth presents the similar quantity, $y^{1}$ assuming $\frac{5}{3} \sqrt{\pi}$ as the constant. The total resulting errors are for column $3,191-68=123$, and for co- 